\title{
COMMENT
}

\section{General models of the spatial distribution of porpoises require representative data and parsimony: Comment on Skov \& Thomsen (2008)}

\author{
Jakob Tougaard*, Mary S. Wisz \\ Aarhus University, National Environmental Research Institute, Department of Arctic Environment, Frederiksborgvej 399, \\ PO Box 358, 4000 Roskilde, Denmark
}

\begin{abstract}
The small-scale distribution of wide-ranging marine top predators has important implications for environmental management. Skov \& Thomsen (2008; Mar Ecol Prog Ser 373:173-186) concluded from a study on Horns Reef, North Sea, that tidally driven upwelling is the most important factor governing distribution of harbour porpoises. For 3 principal reasons such a conclusion cannot be reached through their analysis: (1) the data used are unlikely to be representative of natural and undisturbed conditions of the habitat; (2) the selection of explanatory variables probably led to spurious correlations with no general explanatory value; and (3) there was no assessment of statistical uncertainty, model fit, or parsimony, nor any model validation, and thus no indication of the robustness of the results. Therefore, there is no statistical support for any general conclusions regarding the factors explaining small-scale distribution of harbour porpoises.
\end{abstract}

KEY WORDS: Line transect survey $\cdot$ Phocoena phocoena $\cdot$ Spatial modelling $\cdot$ Offshore wind farms Dynamic habitat modelling

Resale or republication not permitted without written consent of the publisher

Skov \& Thomsen (2008) concluded that 'spatial modelling ... showed the distribution of harbour porpoises to alternate between 2 upwelling cells depending on the direction of the tidal current' (p. 173). In the following we question that such a firm conclusion can be derived by the methods used in the study.

\section{Data selection}

A total of 51 ship surveys were conducted in the Horns Reef area from 1999 to 2005, of which 4 were selected for analysis by Skov \& Thomsen (2008). The surveys were conducted in connection with the construction of a large offshore wind farm (Horns Rev 1, 80 turbines of $2 \mathrm{MW}$ each) in the central part of the study area; 2 of the 4 surveys (28 July and 8 August,
2002) included in the analysis were conducted during considerable construction activities, including a day on which monopiles for turbine foundations were driven into the seafloor (Tougaard et al. 2003). Studies of this particular wind farm and of others have shown a pronounced effect of construction activity on abundance and distribution of harbour porpoises (Tougaard et al. 2003, 2006a,b, Carstensen et al. 2006). Pile driving is a particularly disturbing activity, with effects on porpoises detected $20 \mathrm{~km}$ from the construction site at Horns Rev 1, as documented by the same T-POD data (Tougaard et al. 2009) used by Skov \& Thomsen (2008). These 2 surveys (out of the 4 analysed and 51 available) cannot be taken to represent the undisturbed distribution of harbour porpoises on Horns Reef.

Other reasons for which we suspect that Skov \& Thomsen's (2008) conclusions lack generality are con- 
nected to data dredging in the selection of explanatory variables. Data dredging is an inappropriate application of statistics that can identify effects that seem supported by the data but are actually spurious (reviewed by Anderson et al. 2001). Very little is known about habitat selection in harbour porpoises; ecological theory to guide the selection of explanatory variables is limited and it is difficult to parameterise the models in a realistic way. Skov \& Thomsen (2008) modelled hundreds of predictor variables in relation to a relatively small number of observations. This exacerbates problems associated with spurious effects, and models built in such a way will have high explanatory power within the analysed dataset, but no general relevance beyond the dataset itself. Finally, Skov \& Thomsen (2008) selected surveys that were supposed to provide 'representative coverage of large scale hydrodynamic scenarios' (p. 175), indicating ad hoc selection of data.

\section{Statistical tools}

The final conclusion that tidally driven upwelling is the key factor in determining porpoise distribution was reached by means of 3 analyses: (1) geostatistical analysis of visual sightings, arguing for stratification with tidal phase; (2) partial least squares (PLS) regression analysis of T-POD data, used to screen relevant environmental variables; and (3) ecological niche factor analysis (ENFA) spatial model, used to confirm habitat suitability based on visual survey data and environmental variables selected from the PLS regression analysis.

\section{Geostatistical analysis}

The main argument for stratifying the data according to tidal phase stems from the correspondence between clusters, inferred from the visual sighting variograms, and the spatial extent of the upwelling cells illustrated in Skov \& Thomsen (2008, their Fig. 1), but no information was given on how these upwelling cells were identified or defined. Not only is this correspondence unquantified, the logic is flawed. Based on the fitted variograms in their Fig. 6 we see that the porpoise data are spatially dependent at a scale of up to 6 or $8 \mathrm{~km}$, depending on the survey considered. Skov and Thomsen interpreted this as evidence that analysis at higher resolution is warranted, and that it is valid to explore spatial relationships with fine-scale hydrodynamic features. This seems counter-intuitive to us, because the variograms indicate that data are too spatially dependent to make a valid inference at a spatial resolution finer than 6 to $8 \mathrm{~km}$, due to spatial pseudoreplication/ autocorrelation. Spatial autocorrelation affects parameter estimates and uncertainty estimates in models, and there is a general consensus that predictions and inference from spatially pseudoreplicated datasets are not reliable (Lennon 2000, Diniz-Filho et al. 2003, Segurado et al. 2006, Dormann et al. 2007), and ENFA is not immune to this phenomenon. Numerous tools are available for dealing with spatially autocorrelated datasets (see Dormann et al. 2007 for a review and evaluation), but this issue was not addressed by Skov \& Thomsen (2008) and it is thus impossible to estimate to which degree the results and conclusions of ENFA may have been influenced by spatial autocorrelation.

\section{Partial least squares (PLS) analysis}

The T-POD data were used to select relevant parameters for the habitat suitability model. Even if we ignore the problem of data dredging among $>200$ explanatory variables, there are no model selection criteria (such as Akaike's information criterion), significance tests or any other generally accepted method for building parsimonious models (see Sokal \& Rohlf 1995, Crawley 2002) for any of the analyses in Skov \& Thomsen (2008). PLS variables were instead deemed important merely by the size of their scaled coefficients. The minimal coefficient threshold used to select variables is not described, and there is no explanation of why the top 23 variables were selected and not some other number.

Further, even if we accept the results of the model selection, the logical argumentation that follows does not hold. It is again argued that tidally driven upwelling was the determining factor for porpoise abundance, as indicated by echolocation click activity. However, the correlation analysis was performed on daily averages of click rates and hence it becomes impossible to resolve any tidally driven patterns in abundance because of the lack of fine-scale temporal resolution in the data.

\section{Ecological niche factor analysis (ENFA)}

In the 'Materials and methods', Skov \& Thomsen (2008, p. 178) pointed out that the results of the PLS regression analyses must be considered exploratory, because no assessments of significance could be made. The same applies to the ENFA modelling used to 'confirm' the exploratory PLS results. A variety of robust and well-established methods are available for inferring the relative importance of predictor variables in species distribution models, such as multi-model infer- 
ence (Burnham \& Anderson 1998), or new ensemble modelling approaches implemented in BIOMOD (Thuiller et al. 2009). These methods apply rigorous model selection criteria and the principle of parsimony, and yield uncertainty estimates, and are therefore more appropriate than ENFA to identify determinants of a species' distribution and their relative importance.

\section{Lack of uncertainty estimates, measurements of model fit, and model validation}

Another central problem in Skov \& Thomsen (2008) is the absence of statistical measures of the validity of the results; there is no uncertainty estimate, model selection criterion, significance test or validation of results, although quantitative methods exist for these (for review see Fielding \& Bell 1997, Guisan \& Zimmermann 2000, Guisan \& Thuiller 2005). The support for the hypotheses in Skov \& Thomsen (2008) appears to come from a circular process of visual comparison of the porpoise data and the ENFA model's spatial predictions based on the same data, coupled with marginality indices. The predicted values of the spatial model could have been tested in another area or using a subset of the modelled data (e.g. through bootstrapping, jacknifing or crossvalidation), or using some of the 47 surveys not analysed. Even within the acoustic and spatial datasets analysed, Skov \& Thomsen (2008) did not state which proportion of the variation in the data is explained by the model that was derived, e.g. R or $\mathrm{R}^{2}$ comparing observed and predicted values for the PLS model, and there were no estimates of ENFA's predictive accuracy using e.g. a ROC plot (McPherson et al. 2004). Without such quantitative assessment, it is impossible to assess how well patterns in the data were modelled, and whether the conclusions in Skov \& Thomsen (2008) are robust and representative of general conditions at Horns Reef, or of harbour porpoise behaviour.

We thus find unconvincing support for the conclusions in Skov \& Thomsen (2008) concerning factors that affect the distribution of harbour porpoises. Is tidally driven upwelling an important factor determining fine-scale distribution of harbour porpoises? The results in Skov \& Thomsen (2008) do not provide an answer; until these issues are addressed by appropriate methods, the question remains open.

\section{LITERATURE CITED}

Anderson DR, Burnham KP, Gould WR, Cherry S (2001) Concerns about finding effects that are actually spurious. Wildl Soc Bull 29:311-316

Burnham KP, Anderson DR (1998) Model selection and multi model inference: a practical information-theoretic approach. Springer-Verlag, New York

Carstensen J, Henriksen OD, Teilmann J (2006) Impacts on harbour porpoises from offshore wind farm construction: acoustic monitoring of echolocation activity using porpoise detectors (T-PODs). Mar Ecol Prog Ser 321:295-308

Crawley M (2002) Statistical computing: an introduction to data analysis using S-Plus. John Wiley \& Sons, Chichester

Diniz-Filho JAF, Bini L, Hawkins BA (2003) Spatial autocorrelation and red herrings in geographical ecology. Glob Ecol Biogeogr 12:53-64

Dormann CF, McPherson JM, Araujo MB, Bivand R, and others (2007) Methods to account for spatial autocorrelation in the analysis of species distributional data: a review. Ecography 30:609-628

Fielding AH, Bell JF (1997) A review of methods for the assessment of prediction errors in conservation presence/absence models. Environ Conserv 24:38-49

Guisan A, Thuiller W (2005) Predicting species distribution: offering more than simple habitat models. Ecol Lett 8:993-1009

Guisan A, Zimmermann NE (2000) Predictive habitat distribution models in ecology. Ecol Model 135:147-186

> Lennon JJ (2000) Red-shifts and red herrings in geographical ecology. Ecography 23:101-113

> McPherson JM, Jetz W, Rogers DJ (2004) The effects of species' range sizes on the accuracy of distribution models: ecological phenomenon or statistical artefact? J Appl Ecol 41:811-823

Segurado P, Araujo MB, Kunin WE (2006) Consequences of spatial autocorrelation for niche-based models. J Appl Ecol 43:433-444

Skov H, Thomsen F (2008) Resolving fine-scale spatio-temporal dynamics in the harbour porpoise Phocoena phocoena. Mar Ecol Prog Ser 373:173-186

Sokal RR, Rohlf FJ (1995) Biometry. Freeman, New York

Thuiller W, Lafourcade B, Engler R, Araujo MB (2009) BIOMOD-a platform for ensemble forecasting of species distributions. Ecography 32:369-373

Tougaard J, Carstensen J, Henriksen OD, Skov H, Teilmann J (2003) Short-term effects of the construction of wind turbines on harbour porpoises at Horns Reef. Hedeselskabet, Roskilde

Tougaard J, Carstensen J, Bech NI, Teilmann J (2006a) Final report on the effect of Nysted Offshore Wind Farm on harbour porpoises. Annu rep to EnergiE2. National Environmental Research Institute, Roskilde

Tougaard J, Carstensen J, Wisz MS, Teilmann J, Bech NI, Skov H (2006b) Harbour porpoises on Horns Reef in relation to construction and operation of Horns Rev Offshore Wind Farm. Tech rep to Elsam Engineering A/S. National Environmental Research Institute, Roskilde

Tougaard J, Carstensen J, Teilmann J, Skov H, Rasmussen P (2009) Pile driving zone of responsiveness extends beyond $20 \mathrm{~km}$ for harbour porpoises (Phocoena phocoena, (L.)). J Acoust Soc Am 126:11-14

Submitted: September 28, 2009; Accepted: December 28, 2009 Proofs received from author(s): January 8, 2010
Editorial responsibility: Matthias Seaman, Oldendorf/Luhe, Germany 